\title{
Japanese Rice Straw Community Approaches in Developing Rice Straw Culture (Case Study: Inagaki Wara No Kai, Aomori Prefecture, Japan)
}

\author{
Pandu Purwandaru ${ }^{1}$, Eka Permanasari ${ }^{2}$, Akira Ueda ${ }^{3}$ \\ ${ }^{1}$ Sebelas Maret University, INDONESIA \\ ${ }^{2}$ Universitas Pembangunan Jaya, INDONESIA \\ ${ }^{3}$ Chiba University, Chiba, 263-8522, JAPAN \\ Authors' email: 'pandu@gmail.com, ${ }^{2}$ eka@upj.ac.id,
}

Published: 28 September 2020

\begin{abstract}
The Japanese rice straw culture started from the Yayoi period, the start of wetland rice method of farming technique. The rice straw culture is spread across Japan, as the supply of the rice straw is high, and it does not require special tools to process it. The rice straw culture is performed both during the special events and everyday life. However, along with the modernization and industrialization of agriculture, the culture slowly disappears. It is increasingly difficult to find the rice straw culture in Japan. To prevent this, several rice straw communities create a movement to preserve the culture. Within their methods, the community focuses on pure preservation, preservation and development or pure development. An example of the community focusing on the preservation and development is the Inagaki Wara no Kai. With this method, this community help to preserve the traditional activities of Inagaki village while at the same time creating new events for wider community. The development is rooted in local and global issues and the process of preserving and developing the rice straw culture is documented through workshops, exhibition and festival. These activities are conducted in the cooperation with different stakeholders such as participants, research and development partners, facilitators, or sponsors.
\end{abstract}

Keywords: community, rice straw, development, Japan

eISSN: 2550-214X (c) 2020. The Authors. Published for Idealogy Journal by UiTM Press. This is an Open Access article distributed under the terms of the Creative Commons Attribution-NonCommercial-NoDerivatives License (http://creativecommons.org/licenses/by-nc-nd/4.0/), which permits non-commercial re-use, distribution, and reproduction in any medium, provided the original work is properly cited, and is not altered, transformed, or built upon in any way.

\section{INTRODUCTION}

Based on the FAO (Food Agriculture Organization) data, Japan produced nearly 10 million ton of rice in 2018, made it as one of the most rice producers in the world. Rice has become the main food for the Japanese since Jomon period or the time in Japanese prehistory between 14.000-300 BC. From this rice farm, Japanese has utilized their rice straw waste as part of their culture since the Yayoi era (300BC300AD) optimally (Wiyancoko, 2010). This rice straw culture, known as Wara no Bunka, was highly developed as it had irrigation system which could dry up the land and allow farmers to harvest the rice from its roots and save its stems to be reused. This culture well developed due to several reasons: the abundance and the character of materials, easy production methods using without any specific tools, and supported by the community values which nurture the rice straw culture. The value is represented in two words: (1) mottainai which means 'something should be left as it is even though it is useful and that is shame to waste it; another word is (2) moushiwakenai or the word for apologize from heart in response to using a resource provided by nature in a wasteful fashion (Ueda \& Ooga 2010).

The variety uses of rice straw can be seen from the artefact collections in various museums in Japan. The artefacts may reach up to 2700 collection and categorized based on the needs, such as collection used during the special days namely hare no hi and collection used in everyday occasion namely ke no 
hi (Miyazaki, 1992). The examples of special days products include shimenawa, kadomatsu and other crafts. Meanwhile, the examples of everyday life products include clothing (jacket, sandal, hat and gloves), household utensils (cleaning and nato making tools), architectural (roof and wall), transportation (container and horse equipment) and toys.

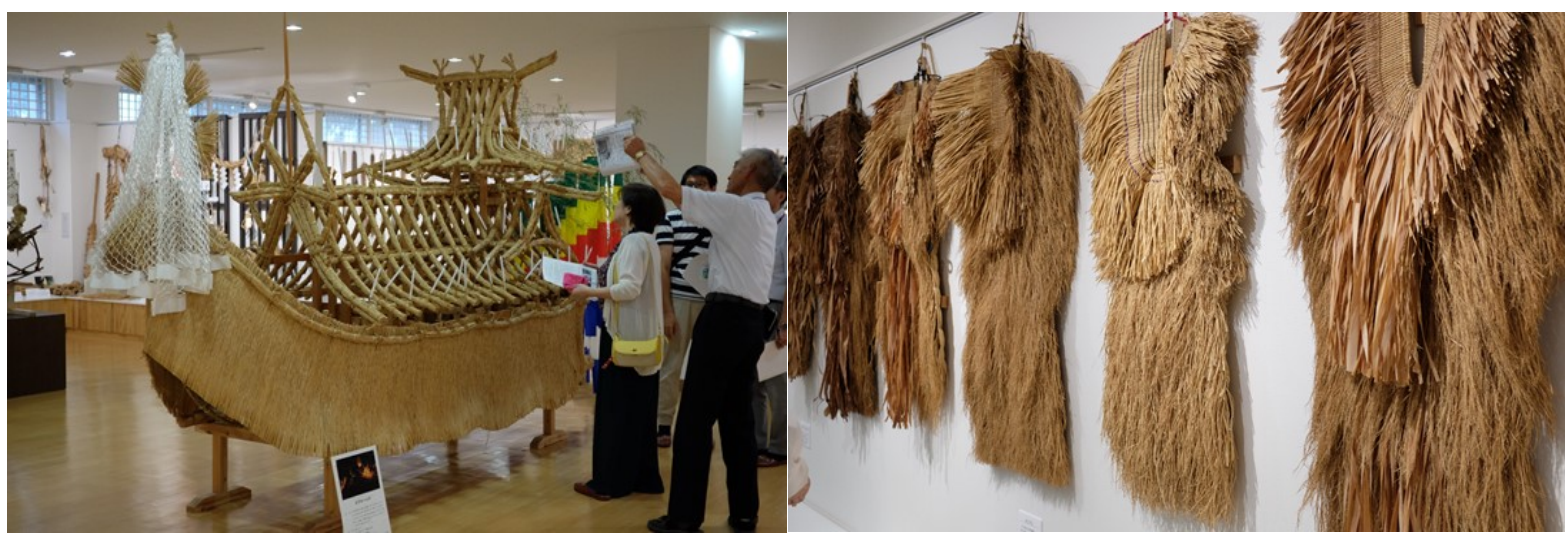

Figure 1: Examples of Japanese rice straw artefacts collection in Misato Town History and

(Source: personal documentation)

Folklore Museum, Akita Prefecture

Despite the significant use of rice straw in special occasion and everyday life, the richness of this culture is threatened by the modernization and globalization. Emeritus Professor Kiyoshi Miyazaki argues that in 1967 there was 2000 places in producing straw rope. Ten years later in 1978, it was only 400 places left. Meanwhile, the straw crafts in 1978 only appeared in 300 workshops. Sadly, now the straw culture nearly disappears. Therefore, there has been massive attempts to preserve this straw culture by establishing several straw communities and preservation organizations. There are three classifications of rice straw community: First, it focusses on preservation only such as Warashibe and Mingikai (Mingu Seisaku Gijutsu Hozonkai) organizations. Second, the community focusses on creating new products like those in Musashino Art University (MAU) and the locals in Niigata city. Third, the community focusses on preserving and development by Inagaki Wara no Kai in Tsugaru city. Out of these three categories, Inagaki Wara no Kai has wider activities including traditional and modern, which impacts on wider audience. Within this method, this organization sustains since 2004 until now. Therefore, this journal analyses the method of Inagaki Wara no Kai in preserving and developing the rice straw culture.

\section{LITERATURE REVIEW}

\subsection{Rice Straw Organization in Japan}

Japanese rice straw organizations were established to preserve and/or to develop the rice straw culture in Japan from its artefact to its values. One of the examples is Warashibe, a rice straw organization established in Yokohama based on the preservation of shimenawa (rice straw rope used for ritual purification) in one of the temples in Yokohama (Mizuno, 2019). Mingikai is an organization which preserves the rice straw culture, bamboo and knitting in Kawasaki. The organization also concerns about the preserving traditional craft values in response to the modernization and globalization (Ankei, 2019). These two organizations focus on exploring traditional artefacts and introduce them to the community through workshop and demonstration.

The activities that focus on only making new crafts like the Musashino Art University have been fully supported by the local community and Niigata city government. They made rice straw festival in Nishikan ward in Niigata City. Big figures of animals and popular icons such as dinosaurs are made out of rice straw and have successfully drawn community's attention to join the festival. Meanwhile, the Inagaki Wara no Kai is the organization that deals with the preservation and development of rice straw 
culture. Their activities include full preservation, cultural development and making new rice straw crafts.

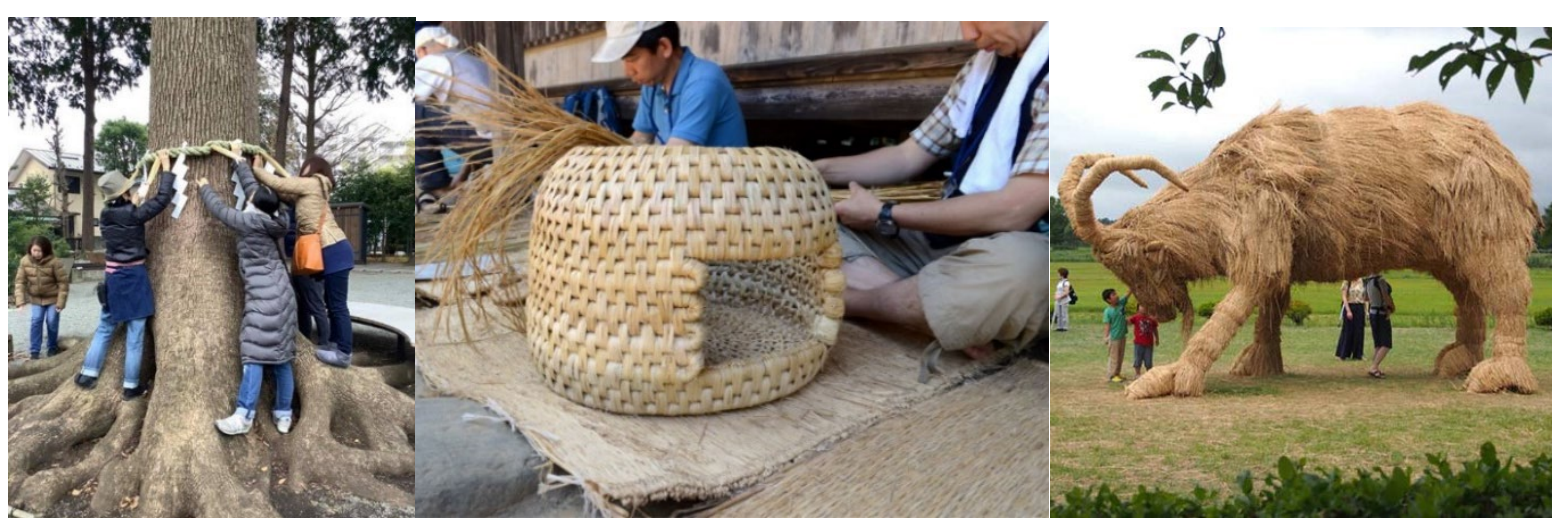

Figure 2: Warashibe activity (left), Mingikai (middle), and MAU (right)

(source: warashibe facebook page, nihonminkaen website, and Niigata city website)

\subsection{Inagaki Wara no Kai}

Inagaki Wara no Kai is the rice straw organization in Inagaki Village, Aomori Prefecture which established in 2004 by Kimihide Nagase and Katsuyuki Nozaki. This organization has 12 members which majority of them came from that village. In the beginning, this organization focused on the preservation, that was collecting the data relating to the artefacts and observed the senior citizen about their rice straw activities. In its initial event implementation to the community, the concept of traditional culture development was implemented. The workshop of making media craft out of rice straw was completed by the school children within 1-2 hours. This included the making of the miniature of kakashi doll (scarecrow). Until now, this organization mainly focuses on the development and dissemination of the Japanese rice straw culture and at the same time continues its activities in supporting traditional activities (Nagase, 2019).

\section{METHOD}

The aim of this research is to analyze the activities and methods of application from Inagaki Wara no Kai in the context of preservation and development. To gain the research data related to the organization and activities, the methods which will be used is direct survey and discussion with all members of Inagaki village community, Aomori Prefecture, Japan. The collected data will be compiled and analyzed by using the tools of reversed method in community development in Jinshin no Hana, previously used by former Professor Naoto Suzuki. These methods are called treasures mapping and stakeholders analysis (Suzuki \& Miyazaki, 2008).

\section{RESULTS}

Inagaki Wara no Kai has an office located in the former school building belong to the government. The office is named as Wa no Gakko which means rice straw school. In its daily activities, Inagaki Wara no Kai positions itself in between NPO and profit organization, as sometimes its activities also receive profit from the workshops, merchandise and external sponsorship from the government or private sectors. The focus of this organization is to preserve and develop the rice straw culture based on the Japanese rice straw culture. Therefore, in order to gather the valid references on how this rice straw culture and its development, the survey is conducted in several places. For instance, to understand the rice straw culture, survey was conducted such as in the community of elderly and high-quality craftsmen in Aomori prefecture, traditional packaging factory in Nara that still using rice straw elements for its traditional cakes, rice straw bag craftsmen in Fujishima city, Yamagata prefecture, and also annual rice straw cultural conference held by Misato Town History and Folklore museum. 
At the same time, the research also analyzes the development of rice straw culture through surveying locations which hold new festivals, workshops and exhibitions which not only related to the usual use of rice straw but also places that could inspire a new utilization of rice straw material. The survey was conducted such as at straw art festival of Sendai city, Miyagi Prefecture and the exhibition of Aomori designer such as Yoshio Mochizuki at the modern art museum. From the information gathered, the design idea was developed internally, with the member of organization and with the partnership of external stakeholders. The design is concluded through the process of consecutive meetings twice a month with kinship approach and open for suggestion. From this design activities, the researchers have classified 2 design approaches, one is concentrating pure on the preservation activities and the other is concentrating on the development activities.

\subsection{Pure Preservation of Traditional Activities}

In the context of pure preservation, the activity approaches are based on the traditional artefacts making in the context of hare no hi (special event day) and ke no hi (everyday) through workshop and supporting traditional activities. The samples of this rice straw culture approach in hare no hi are shown on the internal workshop in making big shimenawa (rice straw rope with particular diameter used for ritual purification in Shinto religion). This new shimenawa is used to replace the old shimenawa displayed at the temple. Other activities related to shimenawa is the small workshop of making shimenawa for families and school children. In the context of culture preservation in hare no hi is the making of mushiokuri, the artefacts of Goshogawara made out of rice straw in the form of dragon by the members of organization as ritual of evil cleansing in the process of rice planting season.
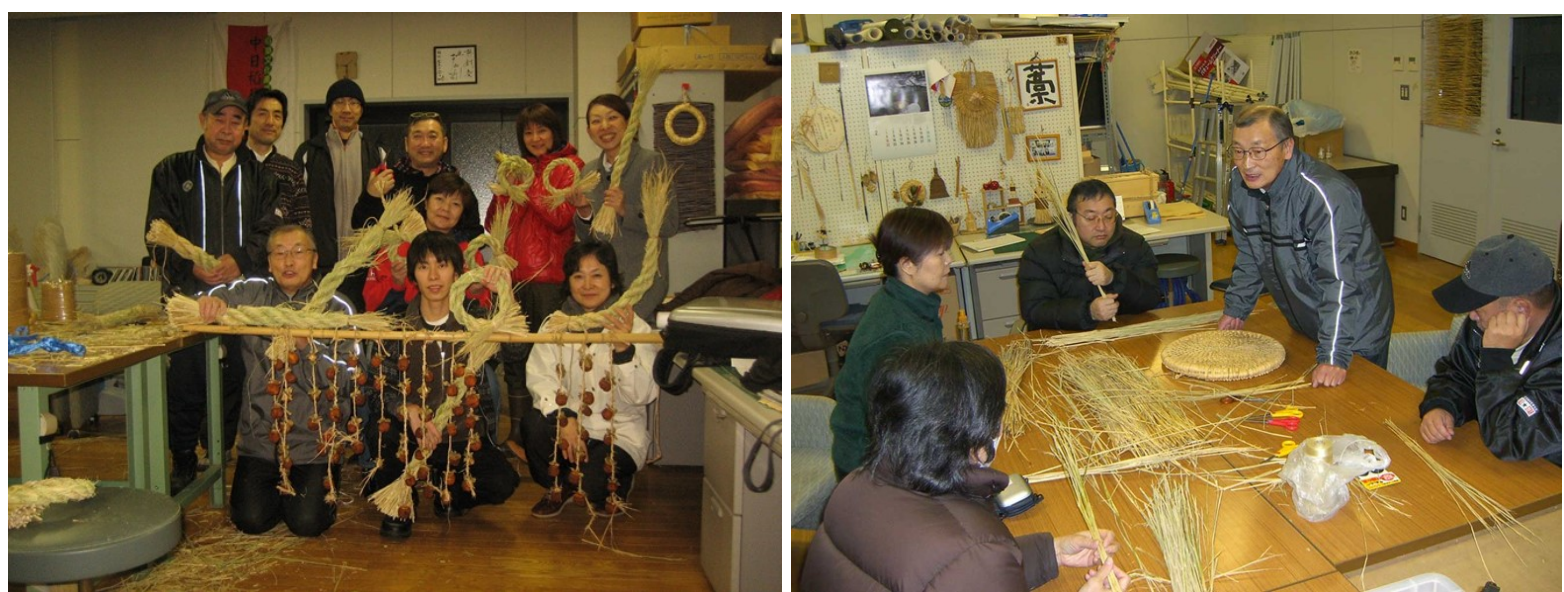

Figure 3: Several activities at Inagaki Wara no Kai in pure preservation of traditional workshops, such as the making of shimenawa and the binder of persimmons (left), and the making of wara enza (right) (source: Document of Inagaki Wara no Kai)

In the context of ke no hi, the activities are majority focusing on the workshops held by internal and external organizations. The example of this internal workshop is the making of the binder of dried persimmon and chili, as well as the making of enza (round seat) led by one of the members who master the process making. Meanwhile, the workshop open for public is the making of rice straw broom whose participants are mostly from the junior high school children and families.

\subsection{Development Activities}

The development activities are conducted within the framework of the rice straw culture development or new product creations. For the development of rice straw culture, the activities focus on making new products based on the function and the traditional artefact values. There are several approaches by Inagaki Wara no Kai, for instance (1) the development of traditional artefact like kakashi (scarecrow) as internal event. With a specific theme, the output is to be used for exhibition decoration which then 
attracts visitors; (2) Other examples are to make merchandise such as mobile phone accessories from the waranawa (rice straw rope), warauma (horse-like toy) displayed with wooden board, the miniature of tamagotsuto (egg container), flower vase and broom to be sold during the exhibition or workshop; (3) In addition, this approach also produces toys which can be played by group of children or adults during the workshop, such as mini kakashi and wanage game (throwing rice straw loop to several sticks). In terms of kakashi workshop, after the craft making is finished, the kakashi is competed between workshop members just like sumo match. The development of traditional based artefacts also used as the basis of organizing internal workshops, such as; (4) the workshop also makes new animal toys as new year celebration with the junishi (Japanese zodiac calender) such as rat, bull, tiger, rabit, dragon, and other zodiacs.

Another development of rice straw is based on the new utilization value. In the implementation of this development is not $100 \%$ new, but rather contains traditional aspects in its production method. The new approaches by the Inagaki Wara no kai include (1) the making of new function of commodity product from rice straw arts and its development including the making of lamp cover from the rice straw paper, drink coaster etc; (2) the adaptation of popular icon such as the making of crafts in the shape of apple as the icon of Aomori prefecture and the making of iconic European dragon statue made out of the rice straw; (3) The city festival in Goshogawara namely Umaichimatsuri displays horse statues made out of rice straw in small and big scales. This festival is part of the local government program in collaboration with several organization to commemorate the role of horses in traditional societies of the past; (4) The internal and external workshops to celebrate the annual celebrations such as Christmas by making shimenawa and other decorations or Halloween by making pumpkin display; (5) The development of the research output from the universities, such as the development of warabou (rice straw stick) based on the research outcome from Chiba University which then furtherly developed by Inagaki Wara no Kai to be their installation art displayed in the exhibition. Other collaboration can also be seen from the Tohoku Institute of Technology which made an eco-fish rice straw doll stuffed with the rice husk ashes to be used as water filter. As part of their research dissemination, they conducted workshop at Inagaki junior high school about the making of this rice straw eco-fish, how to put it on the water stream, and how to dispose it after use by burning and making it as composter (Kondo et al. 2003).

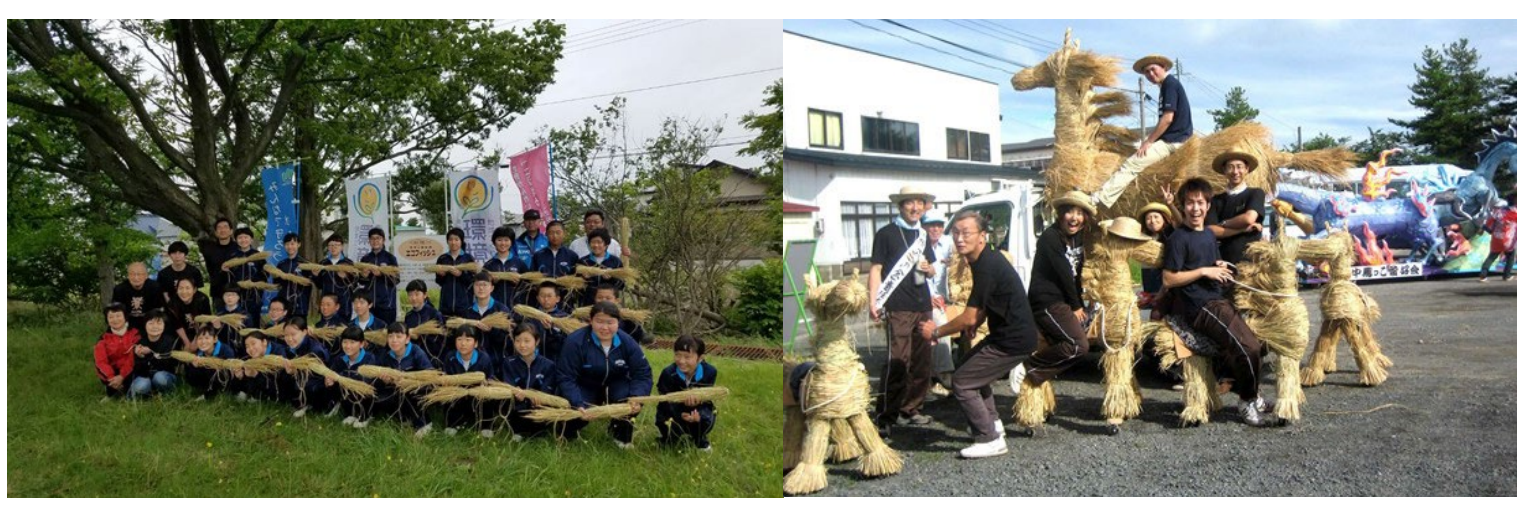




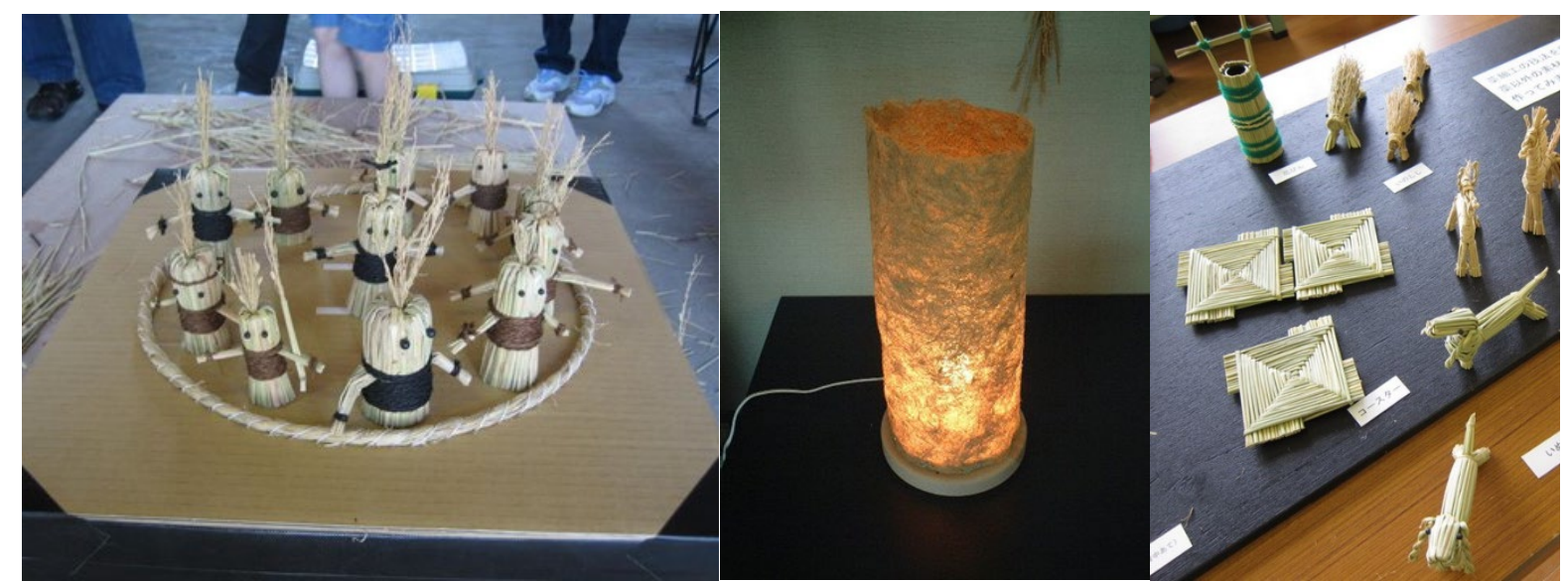

Figure 4: Several examples of developing rice-straw crafts: ecofish (top left), umaichimatsuri festival (top right), mini kakashi (bottom left), straw lamp cover (bottom middle), straw drink coaster and animal dolls (source: Document of Inagaki Wara no Kai)

\section{DISCUSSION}

From the approaches of Inagaki Wara no Kai, it can be concluded that in both preservation and development of the rice straw, the cultural 'treasure' has become the main concern of this community. In the context of development and implementation, the stakeholders play key points for the sustainability of this routine activities.

\subsection{Consideration of Ideas (Treasures Mapping)}

The idea of "treasures" from Inagaki Wara no Kai becomes the foundation in the concept of activities. Currently, there are two elements of main treasures that work as the organization's foundation: the local and global elements. The local elements cover several treasures such as (1) rice straw traditional artefacts which consider the form and use elements; (2) the rice straw production methods from the traditional method making the rope, the woven rice straw and the bundling; (3) rice straw cultural value derived from activities, production and implementation of artefacts for both ritual and everyday uses; (4) the local history consideration which highlights glory of historical culture at Inagaki such as everyday life cultural activities; (5) the farming culture from the seed planting to the crop harvesting as $70 \%$ of Inagaki area is farmland and has historical connection with rice fields; (6) finally, the treasure is invested in the landscape of Inagaki, where the design approach is oriented towards using the natural resources or improving the nature.

On the global notes, the treasures considered are not as much as the local elements. To name view, the elements cover the ideas of: (1) commodity products for general uses in the community and the products have the potentials to be further developed; (2) global annual events such as Christmas and Halloween celebrations; (3) popular culture elements to be used as branding of rice straw culture to the younger generations.

\subsection{Stakeholders}

During the event and exhibition, stakeholders from the community is limited to two categories: internal and external stakeholders. The internal stakeholder consists of community members from the local organizations and other local elements in the area of Inagaki village. This includes general public, education institution and local government. The local community functions as the visitors for the exhibitions, workshops and festival. The government and education institution function as the event organizer and facility providers. The local government functions as the funding provider for the events. 
Meanwhile, the external stakeholder consists of private sectors such as overseas visitors, shopping malls like AEON which allows the exhibition takes place within the mall, and university researchers from Chiba University and Tohoku institute of technology as the partner in the rice straw material development in making crafts in Inagaki region. The rice straw community also creates strong networking through rice straw cultural conference held in Misato town. This has become a medium for ideas exchange and references in the rice straw development.

\begin{tabular}{|c|c|c|c|c|}
\hline APPROACHES & $\begin{array}{c}\text { Preservation } \\
\text { Hare no hi } \\
\text { (special occassions day) and } \\
\text { Ke no hi (regular day) }\end{array}$ & \multicolumn{2}{|c|}{$\begin{array}{c}\text { Development Based on } \\
\text { Traditional Culture } \\
\text { Statue, installation art, merchandise, } \\
\text { games, and animal zodiac dolls }\end{array}$} & $\begin{array}{c}\text { Development Based on } \\
\text { New Values } \\
\text { Commodity products, iconic } \\
\text { based objects, festival, Christ- } \\
\text { mas and Halloween celebration, } \\
\text { research based creation and } \\
\text { workshop }\end{array}$ \\
\hline ACTIVITIES & $\begin{array}{l}\text { Workshops } \\
\text { For internal and external }\end{array}$ & \multicolumn{2}{|c|}{$\begin{array}{l}\text { Exhibitions } \\
\text { Inside and outside Wa no Gakko }\end{array}$} & $\begin{array}{c}\text { Festival } \\
\text { City-scale festival }\end{array}$ \\
\hline $\begin{array}{l}\text { "TREASURES" } \\
\text { MAPPING }\end{array}$ & \multicolumn{2}{|c|}{$\begin{array}{l}\text { Local Elements } \\
\text { Traditional artefacts, production methods, cultural } \\
\text { values, local history, rice farming culture, local } \\
\text { present environment }\end{array}$} & \multicolumn{2}{|c|}{$\begin{array}{c}\text { Global Elements } \\
\text { Commodity products, global events, and popular } \\
\text { culture }\end{array}$} \\
\hline STAKEHOLDERS & \multicolumn{2}{|c|}{$\begin{array}{l}\text { Internal } \\
\text { Organization members, local society, local } \\
\text { government, and local, and educational institutions }\end{array}$} & \multicolumn{2}{|c|}{$\begin{array}{c}\text { External } \\
\text { Private sectors, Universities, Rice straw culture } \\
\text { conference }\end{array}$} \\
\hline
\end{tabular}

Figure 5: Development pattern chart from the Inagaki Wara no Kai

\section{CONCLUSION}

The modernization, globalization and rapid technology invention have diminished human's ability as homo faber, the man having skills of creating tools. This ability will increase awareness in respecting object and nature. To illustrate this, currently Japanese community faces the fact that their rice straw culture is slowly disappearing which impacts the disappearance of skills in producing artefacts and values. Therefore, several organizations have initiated events to preserve and provide new values from this rice straw crafts. This approach shows that Inagaki Wara no Kai is the organization focusing in the preservation and development of rice straw culture. The Inagaki Wara no Kai prioritizes local values in both treasures' references in design and stakeholder's involvement. These elements are the key points in the development and sustainability of cultural-based organization. The true development always recognizes indigenous treasures and people as the core of its driving force.

\section{ACKNOWLEDGEMENTS}

This research is fully funded by the Sumitomo Foundation. We would like to show gratitude for the generosity of the Sumitomo Foundation, so we are able to conduct research both in Japan and Indonesia and publish the research outcomes. We would also like to thank the Inagaki Wara no Kai teams, especially the initiator (Kimihide Nagase) and the organization leader (Katsuyuki Nozaki) who have warmly welcomed us during our data collection.

\section{REFERENCES}

Based on discussion with Kimihide Nagase, Katsuyuki Nozaki and members of Inagaki Wara no Kai, Wa no Gakko, Inagaki village, Japan, August 2019.

Based on discussion with Masahiro Mizuno of Warashibe, Yokohama city, August 2019.

Based on discussion with Nakajima Ankei of Mingu Seisaku Gijutsu Hozonkai (Mingikai) in Japan Open Air Folk Museum, Kawasaki city, Japan, August 2019. 
Kondo, Y., Nagase, K., Sato, T., Enari, K. (2003). The Design of an Ecofish: A Handmade Graywater Purification Tool as a Circulation Type Resource. Journal of the Asia Design International Conference vol.1.

Miyazaki, K. (1992). 葈I、ものと人間の文化史55-14/ Wara I-Mono to Ningen no Bunka-shi 551 (Rice straw - Cultural History of Things and Humans 55-1). Hosei University Press.

Suzuki, N., Miyazaki, K. (2008). Flowering of the Total Person - A Practical Design Philosophy for Indigenous-Led Regional Development. Bulletin of JSSD (Japanese Society for the Science of Design), Vol. 55, No. 1, pp. 37-46.

Ueda, A., Ooga, S. (2010). The Culture of Mottainai Seen as Symbiosis Between Japan's Ceramic Producing Regions and the Natural Environment. Journal of JSSD (Japanese Society for the Science of Design), Vol. 57, No.1, pp.65-74.

Wiyancoko, D. (2010). Design Culture and Cultural Sustainability. Bulletin of Asian Design Culture Society. Issue no.5, pp.561-572. 